\title{
Overview of nuclear waste treatment and management
}

\author{
Jianquan Liu, Wentai Dai \\ College of Energy and Mechanical Engineering, Shanghai University of Electric Power
}

\begin{abstract}
Nuclear energy is an efficient energy source. Nuclear fuel has the advantages of high energy density and convenient transportation and storage. After decades of tortuous development, nuclear energy has been well utilized in many ways, especially in the field of nuclear power generation. However, as the number of nuclear power plants continues to increase, the problem of nuclear waste disposal is becoming more and more serious. Nuclear waste disposal is a complex process. For nuclear waste treatment, people initially only temporarily deposit these nuclear wastes or dump them directly. However, as people's awareness of nuclear waste increases, and the huge potential threat of nuclear waste is known, it is necessary to analyze the current characteristics of nuclear waste and its pollution status in order to find a better nuclear waste treatment and management method.
\end{abstract}

\section{Introduction}

In the past, uranium tailings in the United States have long been unmanaged, and some have been paved with building materials, and some have been poured into dams, causing large-scale pollution. These accidents forced the United States to pass the uranium tailings emission control law in 1987, requiring the tailings to be covered. The US Department of Energy's total budget for 1981 was $\$ 8.326$ billion, of which $\$ 960$ million was used for nuclear waste management, accounting for $8.4 \%$. The nuclear power plant being built in the United States invests $5 \%$ of the total investment in the waste management facility, and the waste management operation costs reach $2 \%$ of the total operating cost of the plant. It can be seen that the high cost of nuclear waste disposal and the strengthening of nuclear waste management can reduce the investment. Due to the high risk of nuclear waste, it is necessary to properly manage the whole process of radioactive waste, reducing and reducing the harm caused by its radioactivity to the environment and humans. Therefore, the research on nuclear waste management has important theoretical and practical significance [1].

\section{Characteristics and types of nuclear waste}

Nuclear waste: Refers to waste that is no longer needed and used in nuclear fuel extraction, production, processing and nuclear reactors. The so-called nuclear waste includes low-level nuclear waste, medium-level radioactive nuclear waste and high-level nuclear waste. The first type is usually some items that are irradiated during the production of nuclear power plants and some waste gas waste; the second type is usually some waste liquid waste generated during power generation; the third type is spent fuel that is replaced from the core. because its utilization rate is only a few percent, it has high radioactivity. When the radiation emitted by nuclear waste passes through the material, ionization and excitation occur. The experience causes radiation damage.

The classification of nuclear waste varies from country to country, but after several decades of development, the following classification methods have been formed [2].

(1) The way to classify elements: can be divided into $\mathrm{Ac}, \mathrm{Th}, \mathrm{Pa}, \mathrm{U}, \mathrm{Np}, \mathrm{Pu}$, etc.;

(2) According to the level of radioactivity, it can be divided into: high level waste, spent fuel, intermediate level waste, low level waste and ultra low level waste;

(3) According to the form of radioactive waste, it can be divided into: radioactive gaseous waste, radioactive liquid waste and radioactive solid waste;

(4) Divided into: Uranium waste and general waste according to whether the radioactive waste contains $\mathrm{E}$ particles and the half-life is more than 20 years.

\section{Hazards of waste}

The main hazard to nuclear waste from humans stems from radioactive radiation. Radiation mainly has somatic effects and genetic effects. The physical effects mainly include: (1) acute injury: damage caused by large doses of the human body in a short period of time; (2) chronic injury: caused by low-dose irradiation of long-term, super-allowable dose limits. (3) Long-term effects: refers to the effects that occur after 6 months of exposure, mainly including leukemia, aplastic anemia, malignant tumors, cataracts, and effects on early fetuses.

\footnotetext{
* Corresponding author: liujianquan@shiep.edu.cn
} 
At the same time, nuclear waste can also pollute the environment. Radionuclides in deep underground nuclear waste emit decay heat during the decay process, which is equivalent to attaching a heat source to the underground medium field. The existence of heat source firstly changes the temperature distribution of the underground medium field, and the temperature change affects the fluid migration by affecting the fluid viscosity and fluid density, and also changes the chemical properties of some substances, thus directly affecting the core of the underground medium field. Mercury migration; in addition, temperature changes may also cause the opening and closing of the crack, which affects the underground stress field. Therefore, the existence of heat sources has a greater impact on the environment, but mainly concentrated in the local areas of the near field. In addition, the nuclides of the solidified solids may be leached from the packaging container, and may enter the biosphere as the groundwater migrates, thereby affecting the human environment [3].

\section{Treatment of nuclear waste}

There are many kinds of nuclear wastes, and different methods must be handled according to different forms or levels of nuclide. It is roughly classified into radioactive waste gas treatment, radioactive waste liquid treatment, and solidification treatment.

The discharge of radioactive waste gas should strictly comply with each radionuclide emission limit of the radiation safety regulations. The radioactive particles are adsorbed and filtered by an air filter device, and the remaining gas is discharged into the atmosphere.

Radioactive waste liquid is most important because of its easy to penetrate, corrosive, and difficult to store. The main treatment methods are chemical precipitation, ion exchange and electrodialysis.

The curing of radioactive waste liquid must achieve two purposes: one is to fix the waste liquid, and the other is to be able to hold the radionuclide for a long time. In order to achieve the above requirements, the cured product should have sufficient resistance to damage. It is easy to transport, store and finalize after curing [4].

\section{Management of nuclear waste}

Nuclear waste management is the administrative and technical activities related to waste generation, pretreatment, treatment, conditioning, storage, transportation, disposal and decommissioning. It is the whole process management from waste generation to disposal. Nuclear waste management must follow certain principles and systems to ensure that nuclear waste is avoided as much as possible during the entire process of production and disposal. Countries have their own management principles in the process of nuclear waste management, but in essence, they all have commonality. Specifically summarized as follows [5]

(1)Protect human health. Nuclear waste management must indeed protect human health to an acceptable level. (2)protect environment. Nuclear waste management must indeed protect the environment to an acceptable level.

(3) Nuclear waste management must take into account the impact on human health and the environment when transferred across national borders.

(4)Protect the offspring. Nuclear waste management must ensure that the health hazards it may cause to future generations are not expected to be greater than today's acceptable levels.

(5) Minimize the burden on future generations. Nuclear waste management must ensure that the current treatment can be handled resolutely, with as little unnecessary burden as possible for future generations.

(6)We should establish a national legal framework. Nuclear waste management must be supported by a corresponding national legal framework.

(7)Control the generation of waste. The generation of nuclear waste must be reasonably minimized.

\section{The current situation and dilemma of nuclear waste management in China}

China' s nuclear energy development started relatively late, from the initial development of national defense nuclear weapons, such as the first atomic bomb explosion test in 1964 and subsequent hydrogen bombs, nuclear submarines, and neutron bombs, to the gradual application of nuclear technology to other fields such as industry, agriculture, and medicine. In the process, a relatively complete nuclear industry system was formed. In the early 1980s, it began to enter the nuclear power generation. In 1991, China's first nuclear power plant independently designed and constructed, Qinshan Nuclear Power Station, was built. After that, the Daya Bay Nuclear Power Plant, the Ling Ao Nuclear Power Station and the Tianwan Nuclear Power Plant were also built. In the 1980s, the application of nuclear technology and radioisotopes was rapidly developed. According to the current actual operation, by 2020 , domestic nuclear power plants will produce about 5,000 cubic meters of solid nuclear waste per year. The technology and capabilities of nuclear waste management are relatively backward, especially in engineering technology and equipment. There are two low- and medium-level solid waste disposal sites in China, which are a disposal site in the northwest and a disposal site in Guangdong in 1998 and 2000. The approved disposal capacity is 60,000 cubic meters and 80,000 cubic meters. It is far below the accumulation of solid waste in nuclear power plants, and the northwest disposal site is not mainly directed to waste generated by nuclear power plants. There are uncertainties in the operation prospects of Beilong disposal sites. China proposes to build a high-level waste disposal repository around 2050 . At present, it is still in the site pre-selection research stage. Based on preliminary comparisons of five pre-selected areas in East China, South China, Southwest China, Inner Mongolia and Northwest China, the focus is on Gansu in Northwest China. Beishan area. 
The main difficulties of China's nuclear waste management are as follows: the current legal and regulatory system is imperfect, the division of management responsibilities of various departments is unreasonable, the technical capacity of nuclear waste disposal is backward, the investment of nuclear waste disposal funds is insufficient, the management of nuclear waste transportation needs to be improved, and nuclear waste The selection of the site of the repository is lagging behind, the talent reserve for nuclear waste treatment technology is insufficient, and a complete safety culture system for nuclear waste management is lacking.

In general, China's nuclear waste management started late, and laws, regulations and regulations have failed to keep pace with the development of nuclear power. Nuclear waste disposal has a weak sense of safety and technology is lagging behind [6]

\section{Analysis and summary of foreign nuclear waste management experience}

The United States has formed a complete system of laws and regulations for nuclear waste management. From the Atomic Energy Law 1954 at the highest level of law to the Nuclear Waste Policy Amendment Act (NEPA) 1969 at the policy level, the Energy Policy Act is supplemented. In addition, the United States is also highly targeted in all aspects of nuclear waste management. The US government has raised nuclear waste management to the same level as nuclear energy development, and nuclear waste management needs to be sustainable. The relevant government departments are responsible for the relevant legislation, approval, and security of the nuclear technology industry, and through the US Department of Energy to initiate and implement various programs to promote industrial development, while the national laboratories and universities carry out future high-tech research and development. At the same time, a strict management and supervision system has been established, and effective government management is an important prerequisite for promoting the healthy and smooth development of nuclear energy. These measures have achieved initial results.

The United States also attaches great importance to the opinions of the people. The typical location of the Yucca Mountain repository is repeatedly put on hold due to opposition from the local state government and the public. The option for the repository may have been cancelled. At the same time, in order to accelerate the development of the nuclear technology industry and provide sufficient talent protection for the nuclear technology industry, the US Department of Energy's Nuclear Energy Program has launched a sub-plan called "University Reactor Infrastructure and Education Assistance" , which is planned to be a university nuclear engineering professional and Research reactors provide support. At present, many universities in the United States have opened or reopened their nuclear engineering programs and increased the number of students enrolled [7].
The UK's laws, regulations and policies on nuclear waste are from nothing, from general to meticulous, from relaxed to strict. Gradually formed a more complete regulatory system. The 1946 Atomic Energy Act of 1946, which enacted the basic principles of nuclear waste management. The Radioactive Material Act was enacted. The Act first established the legal framework for radioactive waste management and assessment standards. In order to better promote the government's efficient management and control of radioactive waste, the Environmental Protection Law was amended in 1990. In 1993, the Radioactive Material Act was revised. Subsequently, the Regulations on the Overseas Transport of Radioactive Waste, the Regulations on the Safety Management of Radioactive Goods Transportation, and the Regulations on the Safety Management of Radioactive Waste were promulgated. In addition to the above-mentioned laws, there is also a special agency

" independent committee" appointed by the government to guide the government's nuclear waste regulations [8]. The White Paper on Safely Managing Radioactive Waste, introduced in 2001, adopted the recommendations of the House of Lords Science and Technology Committee on nuclear waste management policies that should focus on public and stakeholder participation. The UK government has issued a new solid low-level waste management policy in 2007, including: minimizing the production of low-level waste by avoiding, minimizing the use of radioactive materials, increasing recycling and reuse, and establishing National strategy for managing low-level waste in the nuclear industry, including the designation of a nuclear decommissioning agency to develop a plan to "optimize the use of Drig low-level waste facilities, and may require the nuclear decommissioning bureau to establish one (or more) facilities to replace the Drigger repository in the future. The plan for the management of low-level waste in non-nuclear industries was initiated. The first step was to conduct research for the government and the nuclear decommissioning bureau, giving a clear description of low-level waste in the nonnuclear sector. In 2008, the government approved the approval of a new nuclear power project, but the new policy on nuclear waste stipulates that nuclear waste from new projects will also be regarded as legacy waste. The storage site selection can only be for those voluntary areas, that is, those who agree Bury nuclear waste in your own area.

In a word, nuclear waste disposal is a complicated and huge systematic project.It requires a lot of money, advanced technology and long time commitment. Foreign nuclear waste reprocessing plants use cooperative methods to build large factories

\section{8 comments and suggestions}

With the world's massive development of the nuclear energy industry, the number of nuclear power plants has doubled, and several nuclear power plants have been retired. The nuclear waste generated by them is naturally increasing, and countries are paying more and more 
attention to nuclear waste management. New research and construction projects are also being carried out. The management of nuclear waste can be started from the following aspects:

(1) Improve relevant legal and regulatory systems. Nuclear waste management must be supported by sound and supporting laws, regulations and standards. When planning and launching new projects, the relevant higher authorities should increase the formulation of relevant standards so that the standardization work can keep up with the progress of the project so that timely submission can be made. Recommendations for the development and revision of standardized laws and regulations .

(2)Clarify management responsibilities and division of labor. Special nuclear waste disposal companies should be established or outsourced to private individuals to separate the functions of processing, management and supervision.

(3)Strengthen technology research and development. It is necessary to strengthen the research and development of technologies related to nuclear waste disposal, starting from the root cause. The treatment of R\&D personnel should be increased to increase the attractiveness of $R \& D$ positions and the enthusiasm of R\&D personnel.

(4) Established a fund management company. Postprocessing of nuclear waste is not only a business act but also a national act. Government departments should issue management measures for spent fuel reprocessing funds as soon as possible, and establish non-profit thirdparty fund management companies that are independent of nuclear power companies and post-processing companies. The fund management company collects, manages and pays the fund on behalf of the state, and selects a professional company for spent fuel management through contract .

(5) Strengthen transportation management. Nuclear power plants are scattered throughout the country, but the disposal of nuclear waste is concentrated. This inevitably requires the transportation of nuclear waste. The first thing to do with transportation is loading and unloading, followed by loading containers and means of transport, and then protection and management along the way. Strengthen the approval of package design and approval of shipment, and deepen the safety guidelines for the transportation of radioactive waste .

(6) Implement site selection as soon as possible. Accelerate the establishment of site selection requirements and basic guidelines for low- and mediumlevel waste near-surface disposal. The current temporary storage pools are near saturation, and the site selection, construction and operation of low- and medium-level waste disposal libraries should be carried out as soon as possible. For the disposal of high level waste, it is best to choose the vertical borehole stacking method for the deep ground roadway or the lyingway disposal method. This is a deep defense multiple barrier isolation system.
1. Weber W J, Navrotsky A, Stefanovsky S, et al. Mrs Bulletin, 2009, 34(1): 46-53.

2. Wang S A, Alekseev V, Ling J, et al. Chemistry of Materials, 2010, 22(6): 2155-63.

3. Hou X L, Roos P. Analytica Chimica Acta, 2008, 608(2): 105-39.

4. Turick C E, Berry C J. Journal of Environmental Radioactivity, 2016, 151, Part 1(12-21).

5. Salama A, El Amin M F, Sun S. Progress in Nuclear Energy, 2015, 85(747-55).

6. Landa E R. Journal of Environmental Radioactivity, 2004, 77(1): 1-27.

7. Gagnon, Rivest J F, Greenspan M, et al. IEEE Transactions on Instrumentation and Measurement, 1999, 48(3): 758-62.

8. Carrel F, Agelou M, Gmar M, et al. IEEE Transactions on Nuclear Science, 2010, 57(5): 286271.

\section{References}

